\title{
A Study of Connectionism Theory
}

\author{
Shahryar Banan ${ }^{1}$, Muhammad Ridwan ${ }^{2}$, Abdurahman Adisaputera ${ }^{3}$ \\ ${ }^{1}$ Faculty of Foreign Languages, Tehran North Branch, Islamic Azad University, Tehran, Iran \\ ${ }^{2}$ Universitas Islam Negeri Sumatera Utara, Indonesia \\ ${ }^{3}$ Universitas Negeri Medan, Indonesia \\ Shahryar.banan@gmail.com
}

\section{Abstract}

The development of connectionism represents a paradigm shift in science. Connectionism has its root in cognitive and computational neuroscience. Likening the brain to a computer, connectionism tries to describe human mental abilities in terms of artificial neural networks. A neural network consists of a large number of nodes and units which are joined together to form an interconnection network. Within these interconnections, knowledge is distributed. Therefore learning is a processing by-product. This article is about the concept of connectionism, what it accounts for and what it doesn't take into account. Finally, different approaches to connectionism are discussed.
Keywords

connectionism neural networks, interconnection

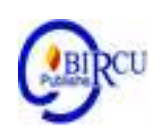

\section{Introduction}

One of science's characteristics is that it is progressive, in constant search of truth. Which seeks theories to explain any natural phenomenon. This characteristic of science results in new paradigms emerging, or what is called paradigm shift. Such a paradigm shift represents the emergence of connectionism. The term connectionism was first mentioned by Thorndike in 1898. But it was not until the early 1980's that connectionist approach became significant in cognitive psychology (Elman, 2008). Connectionism has its root in cognitive and computational neuroscience (Gasser, 1990; Jacobs \& Schumann, 1992). "Cognitive neuroscience refers to attempts to understand the biological bases of mental events, including language .... Computational neuroscience investigates how neural networks interact to process information" (Jacobs \& Schumann, 1992, p. 284). The terms Connectionism, Parallel Distributed Processing (PDP) and Neural Networks are generally seem as being synonymous.

Connectionism tries to explain human mental abilities in terms of artificial neural networks. In other words, it likens the brain to a computer that consists of neural networks. A neural network consists of large number of nodes/units joined together to form a network of interconnections. Each of these nodes can be connected to different networks. Nodes influence the activity of their neighboring nodes at their level or different levels depending on the strength of the connection between nodes. That is each node receives input which may be excitatory or inhibitory from some other nodes. Then it responds to that input by exciting or inhibiting other nodes to which it is connected. The strength of a connection between nodes is often referred to as weight. Knowledge is stored in these interconnections strengths. It follows from this that knowledge is not stored in one place but in the interconnections between the nodes in the form of a network. Knowledge is actually distributed among many interconnections. (Andrade \& May, 2004; Elman, 2008; Mitchell \&Miles, 2004; Ellis, 1994, Thomas \& Karmiloff-Smith, 2002; Waring, 2015). Up to the present time, the bulk of the research into the effects of second language instruction have recorded the linguistic progress of one group exposed to an FonF approach and another exposed to FonFs instruction (Ellis, 
Basturkmen, \& Loewen, 2002; Loewen, 2003). The present study aims to further explore this area, concentrating on the effect that FonF, and FonM have on the acquisition of a grammatical form with communicative value: the six forms of conditional sentences have been selected. Studies on the effectiveness of focus-on-form instruction have increased greatly and suddenly in recent years. Ellis et al (2002) improved Long's (1991) definition of FonF instruction by making the difference between two types: 'Planned focus-on-form' and 'incidental focus-on-form.' In many studies, focus on form was the result of prior planning on. (Alahmad, 44)

Assessment of student is one of the most important responsibilities of teachers, because the quality of teaching in classroom is closely associated with the quality of the applied assessment. Hence it is essential for teachers to possess assessment literacy. Assessment literacy is important because it helps teachers to perceive, analyze and use data on student performance to improve teaching. Stakeholders are influenced by language tests, therefore; being assessment literate is more vital for them, because assessment illiteracy results in inaccurate assessment and consequently the purposes of assessment could not be fulfilled. (Rahimirad, 10)

Mahbobeh Rahmatirad in her article The Effect of Task-Based Syllabus on Iranian EFL Learners asserted:

Also known as the traditional syllabus, it is organized along grammatical items giving primacy to language form. The structural syllabus holds the theory that functionalability arises from structural knowledge. Structural patterns, organized according to such criteria as structural complexity, difficulty, regularity, utility and frequency, are the basic units of learning. It makes an abundant use of highly controlled, tightly structured and sequenced pattern practice drills. It deals with Semantics and sentence types such as statements, questions, interrogatives and grammatically defined types such as simple, compound and complex sentences are seen. Morphology can also be found in structural syllabi such as singular, plural marking; determiners, articles, prepositions, gender markers and so on. (38)

\section{Research Method}

The links become stronger as the associations keep running and they become part of larger networks as connections between elements become more numerous. Clearly the richer the network of associations, the more chance there will be of learning (Elman, 2008; Mitchel $\&$ Miles, 2004; Waring, 2015). This model can account for lack, partial and incorrect storage of knowledge. This can be justified as the strength of the connections between nodes. Items which are not repeated or met frequently have week interconnections. Therefore, constant practice and reinforcement is necessary to strengthen the interconnections (Waring, 2015). Changing the strength of the connections is normally done slowly in response to neural activity. In learning there are successive and/or recursive steps so that the accuracy of the response of the network would improve over time. For example, interlanguage is not considered to be part of L1 or L2 but is progressively and systematically developed as something. It is a system learner constantly updating (or has fossilized) (Poersch, 2005; Waring, 2015, Elman, 2008). Waring (2015) puts the following:

Connectionism rests on the assumption that we learn by trial and error in successive steps, incrementally and through exposure to input. Successive steps in the learning process alter the associative interconnections by strengthening or weakening of the interconnections....As new information is added, new interconnections are made to different 
nodes to account for this. N. Ellis (2006) refers to this property as "variable by variable incremental sequence" (p.15).

Connectionism can account for individual variation. It is believed that each learner has different networks of associations and interconnections even when they share the same L1 and they receive the same input. Therefore, there exists variation among them (Poersch, 2005; Waring, 2015).

\subsection{Complex, Dynamic and Self-Organizing Learning}

The connectionist models of cognitive science are a part of the movement that focuses on explaining the abilities of the human intellect using artificial neural networks, also known as the neural nets. The model follows neuro-anatomy very closely making it extremely useful in understanding the cognitive functioning of human beings. While the classical theory of the mind firmly holds that the human mind resembles a digital computer with its own processing language that it uses to process data, connectionism claims that «cognition is a high-level, emergent phenomena deriving from the interaction of a large number of smaller, individual components». The advantage connectionism has over the classical theory or the language of thought is its close relevance to neurology, which makes it easier to understand the human mind. Connectionism thinks language isn't a collection of modules (syntax, morphology, phonology). Additionally, the construction of linguistic awareness does not underlie rule learning. Learning is argued not to be governed by rules although it shows rule-like behavior. In other words, the PDP system shows rule-like behavior, without any rules. It follows from this that the declarative knowledge as well as the procedural knowledge are coded in network not in the shape of fixed symbols that occupy specified places. Instead, what learners know is characterized in the interconnections between nodes (Ellis, 1994; Poersch, 2005).

The PDP networks are complex, dynamic and self-organizing. They are complex and dynamic in a sense that the nodes are organized into different levels and they change in a continuous manner in which there is never an end state and there is never any state which is totally separate from the next. They are also self-organizing that is the network self-organizes its output. When there is a mismatch between the network's response and the desired response, the information is fed back to the network by a method called back propagation (Andrade \& May, 2004; Ellis, 1994; Elman, 2008; Thomas \& Karmiloff-Smith, 2002). In developmental stages PDP systems are nod good at learning. In general, the network catches the irregularities by rote during the first phase of learning. In the second phase it focuses on regularities governed by rules. In the final phase the net maintains a balance between the two poles of regularity and irregularity and occasionally even overgeneralizes. (Waring, 2015).

Shahryar Banan (2016) in his article The Impact of Enhancing Skewed vs. Balanced Input on Iranian Low Intermediate EFL learners' Knowledge of Verb Use , discusses Some "theory of the child" is necessary, then, to bring the facts about the input - how adults speak to children - and the facts about the output - how children speak - into some sort of responsible alignment. This alignment is what linguistic theory is designed to be about (Chomsky, 1965). Under-standing how environment and nature in this sense come together to explain the course and outcome of language learning is a crucial question. Indeed, it is the only question worth asking in this domain given that children's exposure to a language is finite and limited, and yet they come to say anything they choose (or at least anything they can get away with). 


\section{Result and Discussion}

\subsection{The Pros of Connectionism Theory}

Connectionism is promising to provide a better understanding of the cognitive behaviour than the classical theory because of its association to neuro-science and 'how' and 'how much' change will be brought about has been a matter of great debate in the neuroscientific circles. The experiments on the connectionist models of cognitive science have demonstrated ability to pick-up things and learn skills such as reading, structure of simple grammar in language, and face recognition. This significant similarity to the actual brain gives cognitive models an edge over other traditional theories. The use of connectionist models over the classic theory has many relative advantages and deals with issues like stability, sequence problems and sensitivity.

Due to the close relevance to neurology, the information processed by this type of model for the cognitive functioning turns out to be much more reliable and much more fundamental. The relevance of the connectionist model to neurology has been widely discussed. Scien and Cottrel have claimed that connectionist models definitely have a neurological appeal. Cangelosi has described how the connectionist models consist of the neural networks, which are capable of acquiring categorical perception representations during learning tasks. (Cangelosi, 222-26)

The brain actually resembles a connectionist model of a neural net where instead of numerous units and weights, neurons and synapses form an intricate network. The functioning of the connectionist models has been found to be similar to that of the network of the brain and there is a possibility that these models may give the actual picture of cognitive processing. Neural Net on the other hand is more appropriate, although it may not be totally accurate at times. Neural networks are known to be very flexible and robust in facing challenges but there is evidence that the models face problems in artificial intelligence.

Although connectionist models can also use the existing knowledge base from AI systems, and can handle clinical problems safely, there are certain drawbacks. Connectionists argue that neural networks provide a much more natural mechanism for dealing with such problems. Connectivism is a learning theory that explains how Internet technologies have created new opportunities for people to learn and share information across the World Wide Web and among themselves. A key feature of connectivism is that much learning can happen across peer networks that take place online. Professor Verhagen expands his critique on Connectivism by pointing out the following issues: The introduction of a new approach to learning is not justified, as the main elements of Connectivism can be found within preexisting learning theories .Learning theories should explain phenomena, and those explanations should be verifiable, neither of which Connectivism provides sufficiently nor coherently .Accepting that "learning may reside in non-human appliances" requires a fundamental alteration of the definition "learning", which would make this term meaningless

\subsection{The Cons of Connectionism Theory}

The connectionist models have a lot of potential for the research into the cognitive panorama but there are certain drawbacks, which can be debated in relevance of the classical theory. The systematicity debate over the LOT and the Connectionist models of cognitive science has been around for more than a decade now. In a connectionist model, the weight and the internal patterns create a restriction in the power of the net even with superposition. Ultsch stated that connectionist models were sub-symbolic knowledge representations and the main criterion for such a representation is that no single element has a meaning by itself. 
Like Greene stated that connectionism is only true as an implementation theory, otherwise it is «empirically false as a theory of cognitive architecture». One of the main problems recognized with connectionism is that the information received is too rich and simple. Johnson cited in Garson has stated an argument that the debate of systematicity is misguiding and that any attempt at defining the systematicity of language or cognitive processes would give us falsehoods. Garson has argued that some can argue against the connectionist models stating that the model is inadequate or that it is not able to explain what it must. Hereby, the LOT is the only model of cognition that is computation and thereby, appropriate. Fodor and McLaughlin cited in Aydede have argued that connectionist models are not systematic but can be trained to be systematic. Since there is no guarantee for systematicity, systematicity in the human cognition can't be measured either. And at the same time systematicity is a part of the classical models, which are well structured and coherent. Garson has argued that the nets can be made to do anything one wants, including recognize systematicity, but it cannot be done without implementing the classical symbolic processing.

\section{a. Differences between Traditional Symbolic View and Connectionist View}

In traditional view Language is rule-governed. Language is viewed modular and language learning is seen as mastering the modules. Higher cognitive functions (such as memory) take place in the mind. In connectionist view Language learning is the same as learning other types of knowledge or skills. In this view no distinction is made between competence and performance. Processing takes place simultaneously. Higher cognitive functions (such as memory) are not discussed.

\subsection{Differences of SLA Theories}

In the 1970s the general trend in SLA was for research exploring the ideas of Corder and Selinker, and refuting behaviorist theories of language acquisition. Examples include research into error analysis, studies in transitional stages of second-language ability, and the «morpheme studies» investigating the order in which learners acquired linguistic features. The 70s were dominated by naturalistic studies of people learning English as a second language. Krashen's model was influential in the field of SLA and also had a large influence on language teaching, but it left some important processes in SLA unexplained. Research in the 1980s was characterized by the attempt to fill in these gaps. In the 2000s research was focused on much the same areas as in the 1990s, with research split into two main camps of linguistic and psychological approaches. VanPatten and Benati do not see this state of affairs as changing in the near future, pointing to the support both areas of research have in the wider fields of linguistics and psychology, respectively.

\section{a. Universal Grammar}

The UG model of principles, basic properties which all languages share, and parameters, properties which can vary between languages, has been the basis for much second-language research. From a UG perspective, learning the grammar of a second language is simply a matter of setting the correct parameters. A German speaker learning Italian would only need to deduce that subjects are optional from the language he hears, and then set his pro-drop parameter for Italian accordingly. Once he has set all the parameters in the language correctly, then from a UG perspective he can be said to have learned Italian.

Spanish learners of English who make the mistake «Is raining» instead of «It is raining» have not yet set their pro-drop parameters correctly and are still using the same setting as in Spanish. The main shortcoming of Universal Grammar in describing secondlanguage acquisition is that it does not deal at all with the psychological processes involved 
with learning a language. UG scholarship is only concerned with whether parameters are set or not, not with how they are set. Schachter is a useful critique of research testing the role of Universal Grammar in second language acquisition.

\section{b. Input Hypothesis}

Learners' most direct source of information about the target language is the target language itself. When they come into direct contact with the target language, this is referred to as «input.» When learners process that language in a way that can contribute to learning, this is referred to as «intake». In his Input Hypothesis, Krashen proposes that language acquisition takes place only when learners receive input just beyond their current level of L2 competence. He termed this level of input «i+1. » However, in contrast to emergentist and connectionist theories, he follows the innate approach by applying Chomsky's Government and binding theory and concept of Universal grammar to second-language acquisition. He does so by proposing a Language Acquisition Device that uses L2 input to define the parameters of the L2, within the constraints of UG, and to increase the L2 proficiency of the learner. In addition, Krashen 's Affective Filter Hypothesis holds that the acquisition of a second language is halted if the learner has a high degree of anxiety when receiving input. According to this concept, a part of the mind filters out L2 input and prevents intake by the learner, if the learner feels that the process of SLA is threatening. As mentioned earlier, since input is essential in Krashen's model, this filtering action prevents acquisition from progressing.

\section{c. Sociocultural Theory}

Sociocultural theory was originally coined by Wertsch in 1985 and derived from the work of Lev Vygotsky and the Vygotsky Circle in Moscow from the 1920s onwards. Sociocultural theory is the notion that human mental function is from participating cultural mediation integrated into social activities. The central thread of sociocultural theory focuses on diverse social, historical, cultural, and political contexts where language learning occurs and how learners negotiate or resist the diverse options that surround them. What makes sociocultural theory different from other theories is that it argues that second learning acquisition is not a universal process. On the contrary, it views learners as active participants by interacting with others and also the culture of the environment.

\section{d. Beheverisom Theory}

There is much emphasis on nurture as it focuses on how the environment affects and shapes behavior. This means that the role of nature is ignored, as behaviorists usually ignore that genetic-make up could have an impact on the way in which we behave. Many internal factors govern behavior, one example of this is the role of motivation and emotion are not taken into account in the behaviorist approach. Although this approach has been deemed as overly deterministic, as it suggests behaviors are learnt through associations made with environmental stimuli and/or the response that we get (reinforcement). This view states that the environment controls our behavior and that it's not our conscious thought and processes that governs behavior. There is much emphasis on nurture as it focuses on how the environment affects and shapes behavior. Many internal factors govern behavior, one example of this is the role of motivation and emotion are not taken into account in the behaviorist approach. This view states that the environment controls our behavior and that it's not our conscious thought and processes that governs behavior. 


\section{e. The Three levels of Adequacy of Connectivism Theory}

Observational adequacy: Connectivism exists as an influential phenomenon that inspires teachers and learners to make changes in their practice but will not be built as a theory without significant qualitative studies to inform its development within the context of other theories. Five scenarios are presented that argue for the active and justified choice of theories to support change in the use of technology in teaching and learning.

Descriptive adequacy: Connectivism exists as an influential phenomenon that inspires teachers and learners to make changes in their practice but will not be built as a theory without significant qualitative studies to inform its development within the context of other theories. Five scenarios are presented that argue for the active and justified choice of theories to support change in the use of technology in teaching and learning. Connectivism exists as an influential phenomenon that inspires teachers and learners to make changes in their practice but will not be built as a theory without significant qualitative studies to inform its development within the context of other theories.

Explanatory adequacy: Connectivism is new learning theory that is expanding traditional learning theories (behaviorism, cognitivism and constructivism) in the world that deeply impacted by internet and technology.

\section{Conclusion}

In conclusion, connectionism is mainly concerned with biological explanation of mental abilities and learning process. However, connectionism can be viewed as an interesting cognitive model which is worthy of further exploration.

The connectionist and classical symbolic models may seem to differ on more than a number of factors, but both the approaches work unilaterally to achieve a synthesis of the two apparently different paradigms. Analysis at a very extensive level studies and analyses of the connectionist models reveal relationship to classic symbolic models. More and more researchers are of the view that connectionist and symbolic methods should be combined to achieve significant advances in understanding human cognition. Such integration of the two may be referred to as a hybrid approach that takes representation and techniques from both the models to solve problems efficiently .Cangelosi have also supported the statement by stating that hybrid models are ideal for solving the symbol grounding problem. Both the approaches have their advantages and disadvantages.

\section{References}

Alahmad, Mana. The Role of Form-Focused Instruction on Foreign Language Learners. Budapest International Research and Critics in Linguistics and Education (BirLE) Journal Volume 2, No 4, November 2019, Page: 44-53 . www.bircujournal.com/index.php/birle

Andrade, J., \& May, J. (2004). Cognitive psychology. New York: Garland Science/BIOS Scientific Publishers.

Banan, S. Jahandar. S, Heydarpour, M. The Impact of Enhancing Skewed vs. Balanced Input on Iranian Low Intermediate EFL learners' Knowledge of Verb Use. Modern Journal of Language Teaching Methods 6 (6), 95.2016.

Clark, A., \& Chalmers, D. (2008). The extended mind. Retrieved October 29, 2008, from http://consc.net/papers/extended.html

Connectionism. (2015). In Stanford Encyclopedia of Philosophy online. Retrieved March 29, 2015, from http:// plato. stanford.edu /entries/ connectionism 
Ellis, N. (2006). Language acquisition as rational contingency learning. Applied Linguistics, 27(1), 1-24.

Ellis, R. (1994). The study of second language acquisition. Oxford: Oxford University Press.

Elman, J. L. (2008). Connectionism, artificial life, and dynamical systems: New approaches to old questions. Retrieved October 29, 2008, from http://crl.ucsd.edu/ elman/Papers /companion.pdf

Hadley, A. O. (2003). Teaching language in context. Boston: Heinle \& Heinle Publishers.

Jacobs, B., \& Schumann, J. (1992). Language acquisition and the neurosciences: Toward a more integrative perspective. Applied Linguistics, 13, 282-301.

Mitchell, R., \& Myles, F. (2004). Second language learning theories (3rd ed.). Oxford: Oxford University Press.

Rahmatirad, Mahbobeh. The Effect of Task-Based Syllabus on Iranian EFL Learners. Budapest International Research and Critics in Linguistics and Education (BirLE) Journal Volume 2, No 4, November 2019, Pages: 32-43.www.bircujournal.com/index.php/birle

Rahimirad, Mostafa. The Impact of EFL Teachers' Assessment Literacy on Their Assessment Efficiency in Classroom. Britain International of Linguistics, Arts and Education (BIoLAE) Journal ISSN: 2685-4813 (Online), 2685-4805 (Print) Vol. 1 , No. 1, July 2019, Page: 9-17

O'Brien, G., \& Opie, J. (2002). Radical connectionism: Thinking with (not in) language. Language and Communication, 22(3), 313-329.

Pinker, S., \& Prince. A. (2004). On language and connectionism: Analysis of a parallel distributed model of language acquisition. Retrieved March 29, 2015, from http://users.ecs.soton.ac.uk /harnad/Papers/Py104/pinker.conn.html

Poersch, J. M. (2005). A new paradigm for learning language: Connectionist artificial intelligence. Linguagem \& Ensino, 8, 161-183.

Thomas, M. S. C., \& Karmiloff-Smith, A. (2002). Modeling typical and atypical cognitive development: Computational constraints on mechanisms of change. In U. Goswami (Ed.), Blackwell handbook of childhood cognitive development. (pp. 576-599). Malden: Blackwell Publishers.

Waring, R. (2015). Connectionism and second language vocabulary. Retrieved March29, 2015, from http://www.fltr.ucl.ac.be/fltr/germ/etan/bibs/vocab/connect.html 